\title{
TNF and IL-1 Targeted Treatment in Kawasaki Disease
}

\author{
Florence A. Aeschlimann, $M D^{1}$ \\ Rae S. M. Yeung, MD, $P h D^{1,2, *}$
}

\author{
Address \\ ${ }^{1}$ Division of Rheumatology, Department of Paediatrics, The Hospital for Sick \\ Children, University of Toronto, 555 University Avenue, Toronto, 0N, M5G 1X8, \\ Canada \\ ${ }^{*}, 2$ Department of Immunology and Institute of Medical Sciences, University of \\ Toronto, Toronto, 0N, Canada \\ Email: rae.yeung@sickkids.ca
}

Published online: 8 September 2016

(C) Springer International Publishing AG 2016

This article is part of the Topical Collection on Pediatric Rheumatology

Keywords Vasculitis · Kawasaki disease · Biologic agents · Anti-TNF • Anti-IL-1

\section{Opinion statement}

Kawasaki disease (KD) is a multisystemic vasculitis affecting young children and the most common cause of acquired heart disease in children in the developed world. Current treatment recommendations for acute KD include IVIG and aspirin, but there are no evidence-based guidelines for children who do not respond to IVIG treatment. Widely applicable risk stratification algorithms to identify patients at high-risk of treatment failure and poor coronary artery outcome are not available. Over the past few years, increasing knowledge of the pathophysiology of disease have resulted in the identification of key inflammatory mediators and the use of biologic pathway targeting agents such as TNF and IL1 inhibitors for children with IVIG-resistant disease. However, despite considerable efforts, adequately powered, randomized, controlled and prospective trials are lacking. In this review, we summarize the recent advances in our understanding of disease pathobiology and provide an overview of the currently available studies on anti-TNF and IL-1 therapy in KD.

\section{Introduction}

Kawasaki disease (KD) is an acute, self-limited, systemic vasculitis with predilection for coronary artery involvement and the most common cause of acquired heart disease in children from developed countries $[1 \bullet]$. KD affects mostly young children $<5$ years of age and presents as a multi-system inflammation characterized by prolonged fever, a polymorphous skin rash, induration and erythema of the hands and feet, oral mucosal inflammation, non-exudative conjunctivitis and cervical lymphadenopathy. Epidemiologic studies and clinical observations suggest an infectious trigger: the clinical presentation similar to that in other infectious diseases, the seasonal clustering in winter and spring, temporal clusters of epidemics and the peak incidence between 6 months and 5 years of age [2-4]. Various etiologic agents including viruses, bacterial toxins and 
superantigens have been associated with KD [5-7]. Although a single causative agent has not been linked to acute $\mathrm{KD}$, an infectious trigger is thought to activate an abnormal immunologic response in genetically susceptible individuals [8].

The systemic immune response in $\mathrm{KD}$ encompasses both, the innate and adaptive immune system. Neutrophils and macrophages are involved in the early inflammatory response and release pro-inflammatory cytokines including IL-1 $\beta$, TNF $\alpha$ and IFN $\gamma$ with, pleiotropic, down-stream effector functions. Both TNF $\alpha$ and IL-1 $\beta$ have been associated with vascular endothelial cell damage and coronary artery lesions in acute KD [9]. Antigen presentation and co-stimulation lead to $\mathrm{T}$ cell activation with further significant increase of pro-inflammatory cytokine production. To date, recommendations for the treatment of acute KD consist of aspirin and intravenous immune-globulin (IVIG) [1•]. IVIG decreases the risk for coronary artery aneurysms formation from 25 to $5 \%$, in those appropriately treated [10•]. Approximately 20-30\% of children do not respond to standard treatment and develop persistent or recrudescent fever after a single dose of IVIG [11-13]. This subgroup of children has the highest risk to develop coronary artery lesions [ $1 \bullet$. Various predictors of poor outcome such as male gender, higher C-reactive protein, worse anemia, lower serum albumin and serum sodium have been included into different scoring systems to assess the severity of KD and the risk of IVIG resistance [14-16]. None have been widely accepted or valid outside of Japan. More recent treatment approaches aimed at early identification of these high-risk patients and those presenting with coronary artery lesions by escalation of the initial anti-inflammatory treatment $[17,18,19 \bullet \bullet]$. However, despite the use of risk stratification algorithms, these treatment approaches are often too late and coronary artery damage already present.

Upregulation of TNF $\alpha$ and IL-1 $\beta$ and their associated downstream effector molecules have been shown to play crucial roles in the mediation of systemic inflammation and coronary artery damage in $\operatorname{KD}[9,20]$. Understanding of these underlying pathophysiologic mechanisms build the rationale for the more recent, biologic pathway-targeted therapeutic approaches, which we will discuss in this review.

\section{Tumor necrosis factor alpha}

$\mathrm{TNF} \alpha$ is a prototypic pro-inflammatory cytokine, mainly produced by activated macrophages, although other cell types including dendritic cells and T cells can also produce TNF $\alpha$. TNF $\alpha$ levels in the serum/plasma are unstable [21-23]. The reliability and reproducibility of TNF $\alpha$ detection may be influenced by various factors including blood collection tubes, processing and storage conditions and the type of assay used, and these factors need be taken into account when evaluating TNF $\alpha$ measurements in the context of clinical research [21,22]. The key role of TNF $\alpha$ in the mediation of inflammation during the acute phase of KD has been reported in several studies. Significantly elevated serum levels of TNF $\alpha$ and soluble TNF receptor have been demonstrated in children with acute $\mathrm{KD}[24,25]$ and including those with coronary artery aneurysms [26]. A recent report found no difference in the TNF $\alpha$ levels of children with and without coronary artery aneurysms pre-IVIG treatment [27]. However, after IVIG treatment, TNF $\alpha$ levels increased in children who did not respond to IVIG and in those with coronary artery lesions, but they decreased in children without coronary involvement [27].

\section{TNFa downstream effectors}

In addition to TNF $\alpha$ itself, its downstream effector molecules are key players in the mediation of systemic inflammation and coronary artery damage [28-31]. TNF $\alpha$ signalling leads to nuclear translocation of NF-kB and increased expression of various gene products. These include cell proliferation, leukocyte recruitment molecules, other pro-inflammatory cytokines, acute phase reactants and proteases, such as matrix metalloproteases (MMP) [32-34]. Several downstream effects of TNF $\alpha$ have been directly linked with systemic and local inflammation as well as coronary artery damage and are described in detail below.

$T N F \alpha$-mediated leukocyte migration is necessary for coronary artery inflammation [28]. Leukocyte migration is a highly coordinated process that is regulated by chemokines and adhesion molecules and follows three steps: leukocyte rolling, firm adhesion and transendothelial migration $[33,35]$. The interaction between vascular endothelium and leukocytes leads to a local inflammatory response. Increased expression of the chemokine RANTES and of adhesion molecules including ICAM- 1 and E-selectin has been found in children with acute $\operatorname{KD}[36,37]$. The critical role of TNF $\alpha$-mediated expression of leukocyte recruitment molecules has also been 
demonstrated in a KD mouse model [28]. Hui-Yuen and colleagues reported that $\mathrm{T}$ cell activation leads to TNF $\alpha$ expression in the peripheral immune system [28]. This was followed by in situ production of $\mathrm{TNF} \alpha$ in the coronary artery vessel wall, which coincided temporally and spatially with the presence of maximal lymphocyte infiltration into the coronary arteries. Persistent TNF $\alpha$ production and local immune response resulted in elastin degradation, vessel wall damage and the characteristic coronary artery lesions seen in KD. Interestingly, when TNF $\alpha$ activity was blocked, either by treatment with the TNF $\alpha$ inhibitor (etanercept) or by abolishing the TNF $\alpha$ signalling pathway by use of TNFRI knockout mice, local inflammation and elastic breakdown of the coronary arteries were ameliorated [28].

Increased expression of proteases, especially MMPs, is another important downstream product of TNF $\alpha$ signalling. MMPs are a family of proteolytic enzymes that are able to destroy the extracellular matrix by degradation of collagen and elastin fibers. MMPs are regulated at multiple levels and controlled by many factors, and among others by TNF $\alpha$ [38]. MMP-9 has been found to be localized to both coronary artery aneurysms and unaffected coronary artery segments of fatal human KD cases [39]. As MMP-9 was not expressed in coronary arteries from non-KD controls, the authors suggested that MMP-9 plays a critical role in the development of aneurysms in KD. The upregulation of MMP-9 expression by local inflammation and in situ production of TNF $\alpha$ has been demonstrated in a KD mouse model [29]. Abolishing the MMP-9 activity significantly reduced coronary artery lesions despite ongoing inflammation. MMP-9 appears to be a key downstream effector molecule, produced as a result of the local inflammatory response, and the critical link between inflammation and the coronary artery damage [29].

Production of pro-inflammatory cytokines is another key downstream effector function of TNF $\alpha$ important in the pathogenesis of $\mathrm{KD}$. One of these proinflammatory cytokines is IL-6. IL-6 levels are elevated in $\mathrm{KD}$ patients and associated with various biologic effects including increased acute-phase proteins, T cell activation, procoagulant effects and thrombocytosis [40]. In addition, IL-6 can upregulate the production of MMP-9 through platelet activation [41].
Agents able to inhibit TNF $\alpha$ and/or its downstream effector functions such as TNF $\alpha$ inhibitors, or MMP inhibitors such as ulinastatin (a neutrophil elastase inhibitor), doxycycline (antibiotic with MMP inhibiting function) or novel MMP small molecule inhibitors have proven effective in preventing coronary aneurysms in pre-clinical disease models and offer promising treatment strategies in children with KD [28-31].

\section{Interleukin-1 $\beta$}

During the past few years, IL-1 $\beta$ has been increasingly recognized to play a pivotal role in various diseases [42]; among them the recurrent fever syndromes in childhood, in which many have been found to be monogenic in origin leading to abnormal regulation of innate immunity $[43,44]$. IL- $1 \beta$ shares many biological functions with $\mathrm{TNF} \alpha$ [45] and like TNF $\alpha$, macrophages are the main source of IL-1 $\beta$ production, but neutrophils, epithelial cells and endothelial cells are also able to produce IL- $1 \beta$. In comparison to TNF $\alpha$, IL- $1 \beta$ is more stable in the blood [21]. IL-1 $\beta$ is synthesized as the inactive IL-1 $\beta$ precursor that is enzymatically cleaved by caspase- 1 releasing the active cytokine [46]. Caspase-1 is activated by the action of the inflammasome, a large intracellular multi-molecular complex. Clinical and animal studies have provided evidence for the critical role of inflammasome activation and IL- $1 \beta$ production in KD. Maury et al. reported that serum levels of IL- $1 \beta$ were significantly elevated in children with KD compared with age-matched healthy controls [20]. Investigation of gene-expression patterns in KD patients revealed an increased relative abundance of gene transcripts associated with innate immune and pro-inflammatory response, including the IL-1 $\beta$ gene [47]. Increased IL-1 $\beta$ gene expression and diminished IL-1RA expression have been demonstrated in IVIG resistant patients [48]. An association of IL-1 $\beta$ polymorphism resulting in increased IL-1 $\beta$ secretion and IVIG resistance has recently been reported [49]. These data are further supported by observations that IVIG treatment in children with KD is associated with a reduction of IL- $1 \beta$ secretion (in vivo) and that IVIG is able to downregulate IL- $1 \beta$ and to upregulate IL-1RA production in vitro [50-52].

More recently, a possible link between a single nucleotide polymorphism and increased IL-1 $\beta$ production has been suggested. A genome-wide association study discovered a single nucleotide polymorphism in the inositol 1,4,5-triphosphate 3 kinase (ITPKC) gene, which was 
associated with increased risk of $\mathrm{KD}$ and development of coronary artery aneurysms [53]. ITPKC negatively regulates the intracellular $\mathrm{Ca} 2+$ influx that plays a crucial role in the NLRP3 inflammasome activation. The single nucleotide polymorphism in the ITPKC gene results in a sustained elevation of intracellular $\mathrm{Ca} 2+$ and thus in an increased NLRP3-inflammasome activation leading to IL$1 \beta$ production. These mechanisms provide a possible link between the single nucleotide polymorphism in the ITPKC gene and KD [54-56]. A large genomic study investigated whole blood transcriptional profiles of 146 acute KD subjects compared to non-KD pediatric patients and also revealed the importance of the IL-1 related pathways in children with KD [57•].

The role of IL-1 $\beta$ in the induction of coronary artery inflammation has recently been further elucidated in a mouse model of KD. Lee and colleagues demonstrated that IL-1R-deficient mice and caspase-1-deficient mice are not affected by coronary arteritis indicating the key role of IL-1 $\beta$ in the pathogenesis of coronary artery lesions [58]. Additionally, treatment with IL-1RA significantly blocked development of coronary artery lesions and it decreased overall myocardial inflammation [58]. While anti-TNF therapy was also able to prevent coronary artery lesions, it did not reduce the incidence of myocarditis in the animal model. Taken together, IL-1 blockade showed a trend towards more effective inhibition of coronary artery damage and myocarditis compared to TNF blockade in this murine model of KD [58]. The same group reported that both IL-1 $\beta$ and IL- $1 \alpha$ are essential for the development of coronary arteritis in the same KD mouse model and concluded that therapeutic agents should target both IL- $1 \alpha$ and IL-1 $\beta$ [59].

\section{IL-1 $\beta$ downstream effects}

IL-1 $\beta$ regulates the transcription of several downstream effector molecules resulting in its pleiotropic effects. IL$1 \beta$ is the most pyrogenic of the fever-inducing cytokines and stimulates the bone marrow leading to a release of neutrophils [60]. Similar to TNF $\alpha$, IL- $1 \beta$ is able to activate inflammatory processes and the production of IL-6, which likely accounts for the rise in acute-phase proteins and thrombocytosis [61]. IL-1 $\beta$ signalling is regulated through type I IL-1 receptor. Either natural IL-1 receptor antagonist (IL-1RA) or the therapeutic recombinant molecule (anakinra) can block IL-1 receptors and prevent normal IL-1 signalling [62]. Therapeutic IL-1 blockade has been successfully used in murine model of KD $[58,59,63,64]$ and by the KD community for treatment of treatment resistant $\mathrm{KD}$.

\section{Treatment}

A few case series and small clinical trials have reported potential beneficial effects of TNF blockade in children with KD (Table 1). Beneficial effects were observed specifically regarding duration of fever, length of hospital stay and normalization of acute phase reactants after a single dose of infliximab in children who failed IVIG $[10 \bullet, 65]$. However, none of them reported improved coronary artery outcome with the use of infliximab $[10 \bullet, 65,66]$. A retrospective study evaluated the use of a single infliximab infusion $(5-10 \mathrm{mg} / \mathrm{kg})$ in children resistant to at least two doses of IVIG [67]. Treatment response, measured as defervescence of fever was observed in 13/16 children. CRP levels were elevated in all except one child prior to the infliximab infusion, and CRP levels decreased after infliximab in all 10 children in whom it was re-measured within $48 \mathrm{~h}$ of treatment. Infliximab treatment was reported to be safe and well tolerated [67]. A small multicenter, randomized, prospective trial compared IVIG infusion $(2 \mathrm{~g} / \mathrm{kg})$ to infliximab $(5 \mathrm{mg} / \mathrm{kg})$ in 24 children with $\mathrm{KD}$ refractory to a single dose of IVIG [66]. Four of the 13 children (31\%) randomized to a second IVIG infusion required additional therapy with infliximab, while $3 / 16$ children (19 \%) who received infliximab as either second- or third-line treatment 


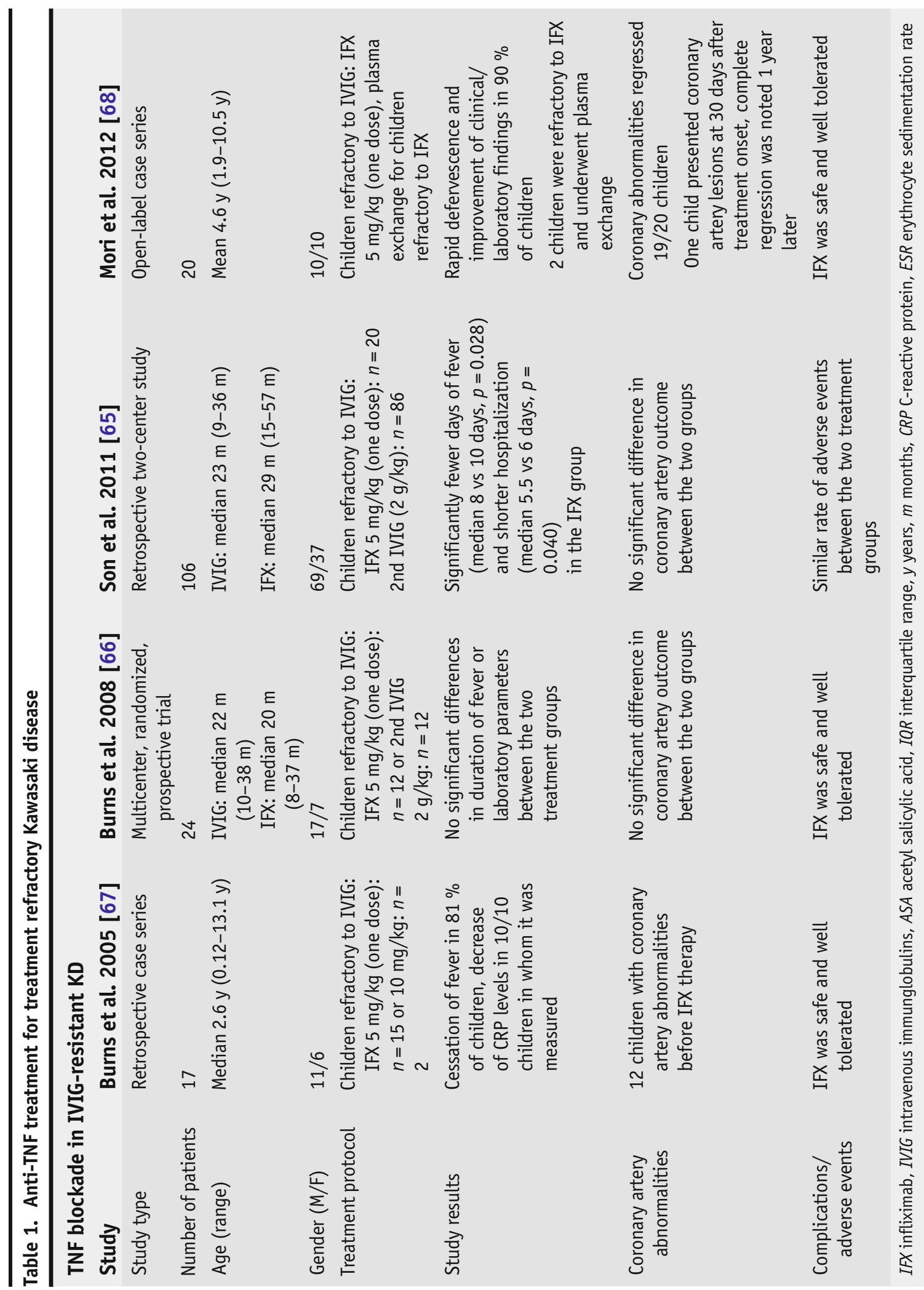


required additional medication. No significant differences were observed between the treatment groups in time until defervescence, change of laboratory variables and coronary artery abnormalities reported as body surface area normalized z-scores. Five children developed coronary artery aneurysms (four randomized to infliximab and one to IVIG), however in four of them coronary artery abnormalities were already present at study entry. Infliximab appeared well tolerated and no serious adverse events were attributed to the treatment [66]. In a more recent retrospective review of IVIG-resistant KD, treatment with infliximab $(n=20$ children) was associated with fewer days of fever (median 8 vs. 10 days; $p=0.028$ ) and shorter hospitalization (median 5.5 vs. 6 days, $p=0.040$ ) compared to retreatment with IVIG ( $n=86$ children). The rates of coronary artery aneurysms and adverse events were similar in both treatment groups [65]. It is unclear whether the patients in the previous retrospective study [66] were a subset of the patients reported in the second retrospective study [65]. Mori and colleagues treated 20 Japanese children who had failed IVIG with infliximab $5 \mathrm{mg} / \mathrm{kg}$ in an open-label trial [68]. Eighteen children showed a rapid decrease of fever (within $24 \mathrm{~h}$ ) as well as decrease of the number of inflammatory symptoms and normalization of the inflammatory markers within 3 days after infliximab. Two patients required plasma exchange to prevent coronary artery damage, as they were refractory to infliximab. Coronary abnormalities including increased echogenicity and mild dilatation were noted in all patients at baseline and regressed in all but one child within 30 days after therapy. One child progressed to develop a coronary artery aneurysm at 30 days, but had a complete regression of the coronary artery lesion 1 year later. There were no reports of adverse events [68]. Another study investigated the dynamic changes of cytokines during infliximab treatment in children with KD [69]. Although serum levels of proinflammatory cytokines decreased dramatically after infliximab, markers of local tissue damage were not suppressed. In contrast, successful IVIG treatment markedly decreased all measured soluble mediators of inflammation. The authors concluded that proinflammatory cytokines and markers of local tissue damage respond differently to infliximab and suggested that infliximab is effective for suppression of systemic cytokine-mediated inflammation, but could not completely inhibit local inflammation at the coronary arteries [69]. The findings regarding systemic inflammation are supported by recent data showing that levels of TNF $\alpha$ and many other proinflammatory mediators decreased in IVIG-resistant children who responded to infliximab, whereas they did not decrease in infliximab non-responders [70]. In particular, IL-6 and IL-10 were insufficiently suppressed in non-responders. The authors suggested that inflammatory mechanisms other than the TNF $\alpha$ pathway are at play in infliximab-refractory children.

Anti-TNF agents have also been investigated for intensification of primary therapy in KD (Table 2) [10•, 71]. In a phase 3, randomized, doubleblind, placebo-controlled trial comparing IVIG to IVIG plus infliximab $(5 \mathrm{mg} / \mathrm{kg})$, the addition of infliximab did not significantly reduce treatment resistance nor improve coronary artery outcome, although the trial was underpowered for this endpoint [10•]. However, the IVIG + infliximab group had shortened duration of fever and more rapid reduction of 
Table 2. Anti-TNF treatment for primary treatment of Kawasaki disease

\begin{tabular}{|c|c|c|}
\hline Study & Tremoulet et al. 2014 [10•] & Choueiter et al. 2010 [71] \\
\hline Study type & $\begin{array}{l}\text { Phase 3, randomized, double-blind, } \\
\text { placebo-controlled trial }\end{array}$ & Prospective open-label trial \\
\hline Number of patients & 198 & 15 \\
\hline Age (range) & $\begin{array}{l}\text { IFX: median } 3.0 \text { y (IQR } 1.9-4.8 \text { y) } \\
\text { Placebo: median } 2.8 \text { y (IQR 1.8-4.2 y) }\end{array}$ & Mean 2.6 y $(9 \mathrm{~m}-4.8 \mathrm{y})$ \\
\hline Gender (M/F) & $121 / 75$ & $8 / 7$ \\
\hline \multirow[t]{2}{*}{ Treatment protocol } & $\begin{array}{l}\text { Standard therapy (IVIG } 2 \mathrm{~g} / \mathrm{kg}+\text { ASA } \\
80-100 \mathrm{mg} / \mathrm{kg} \text { ) PLUS }\end{array}$ & $\begin{array}{l}\text { Standard therapy (IVIG } 2 \mathrm{~g} / \mathrm{kg}+ \\
\text { ASA } 80-100 \mathrm{mg} / \mathrm{kg} \text { ) PLUS }\end{array}$ \\
\hline & $\begin{array}{l}\text { IFX } 5 \mathrm{mg} / \mathrm{kg} \text { (single dose) or standard } \\
\text { therapy PLUS placebo }\end{array}$ & $\begin{array}{l}\text { ETN } 0.4-0.8 \mathrm{mg} / \mathrm{kg} \text { at day } 1,7, \\
\text { and } 14 \text { after IVIG }\end{array}$ \\
\hline \multirow[t]{2}{*}{ Study results } & $\begin{array}{l}\text { Fewer days of fewer (median } 1 \text { vs } 2 \text { days, } \\
p<0.0001) \text {, greater mean reduction } \\
\text { of CRP }(p=0.0003) \text { and absolute } \\
\text { neutrophil count }(p=0.024) \text { at } 24 \text { h } \\
\text { after treatment and of ESR }(p=009) \\
\text { at } 2 \text { weeks }\end{array}$ & Defervescence in all children \\
\hline & $\begin{array}{l}\text { No significant difference at } 5 \text { weeks } \\
\text { after treatment }\end{array}$ & Normalization of CRP at day 7 in all children \\
\hline \multirow[t]{2}{*}{$\begin{array}{l}\text { Coronary artery } \\
\text { abnormalities }\end{array}$} & $\begin{array}{l}\text { Greater decrease in Z score of left } \\
\text { anterior descending artery }(p=0.045) \\
\text { at week } 2 \text { after treatment, but no } \\
\text { significant difference at week } 5\end{array}$ & $\begin{array}{l}\text { No new coronary artery aneurysm/dilatation } \\
\text { or cardiac dysfunction observed during } \\
\text { study period }\end{array}$ \\
\hline & $\begin{array}{l}\text { No significant difference for the } \\
\text { proximal right coronary artery } \\
\text { Z score at any time point }\end{array}$ & $\begin{array}{l}\text { Five children had coronary artery lesions at } \\
\text { baseline, in } 3 / 5 \text { decrease of the z-score } \\
\text { was observed within } 6 \text { weeks, } 1 / 5 \text { resolution } \\
\text { of the aneurysms was seen at } 6 \text { months }\end{array}$ \\
\hline $\begin{array}{l}\text { Complications/ } \\
\text { adverse events }\end{array}$ & Infliximab was safe and well tolerated & ETN was safe and well tolerated \\
\hline
\end{tabular}

inflammation $[10 \bullet]$. Intensified primary treatment with IVIG and etanercept $(0.8 \mathrm{mg} / \mathrm{kg}$ weekly for three doses) has been reported to be safe and well tolerated in 15 children with KD [71]. Another, larger multicenter, double-blind, randomized and placebo-controlled trial assessing the efficacy of etanercept in addition to IVIG in acute KD is currently in progress (NCT00841789).

There are several concerns related to the use of TNF inhibitors in children with $\mathrm{KD}$, chief among them infection and malignancy. The risk-benefit profile of TNF inhibitors in the early, acute phase of KD is unclear. Infectious agents responsible for triggering KD are commonly still present during acute KD [72], and active infections are a contraindication to the use of TNF inhibitors. In refractory disease, where the exaggerated immune response as opposed to the infectious agent, likely drives the inflammatory response, 
the benefits may outweigh the potential infectious risk. The risk of malignancy after a single dose of infliximab as used in most of the children with $\mathrm{KD}$ is not known. Additionally, various other concerns regarding the use of TNF blockade in children with KD remain unsolved: there is a lack of clear dose recommendations for infants and children, absence of long-term safety data and paucity of treatment efficacy in preventing coronary artery aneurysms. Future prospective, randomized clinical trials are needed to clarify the role and efficacy of TNF blockers as primary and rescue treatment of KD.

Besides TNF inhibition, treatment approaches have been directed towards the TNF $\alpha$-mediated downstream effects with MMP-9 and associated elastolytic activity as one such potential therapeutic target. Ulinastatin, a neutrophil elastase inhibitor, has been associated with better treatment response and reduced coronary artery lesions when used as therapeutic agent together with IVIG and aspirin [73]. Ulinastatin is recommended as second-line treatment in Japan for IVIG-resistant KD [74•]. Other MMP inhibitors found to be effective in pre-clinical models of KD have also moved to the bedside [30, 76]. The efficacy and safety of doxycycline, an antibiotic with MMP inhibiting function, is currently evaluated in a small pilot study in KD children with coronary artery lesions (NCT01917721). Atorvastatin, a 3-hydroxy-3-methylglutaryl (HMG) coenzyme A (CoA) reductase inhibitor and commonly used lipid lowering agent, also has antiinflammatory and endothelial-healing properties that may improve coronary artery outcome [75]. Atorvastatin has been shown to inhibit TNF $\alpha$ mediated MMP-9 production and to reduce T cell activation in pre-clinical models $[75,76]$. Based on these findings, Atorvastatin is currently investigated in two studies including children with coronary artery abnormalities secondary to KD (NCT01431105, NCT02114099).

To date, two case reports have been published reporting the successful use of anakinra, an IL-1 receptor antagonist inhibiting both IL- $1 \alpha$ and IL-1 $\beta$, in children with refractory KD $[63,64]$, but many more cases of treatment resistant disease receiving IL-1 blockade have been reported in online discussions. Cohen et al. reported a 2-year-old boy with severe, relapsing KD, who responded twice to anakinra [63]. The boy relapsed and his clinical and coronary findings rapidly deteriorated after discontinuation of anakinra. When the IL-1 blockade was restarted, he rapidly improved. Interestingly, the coronary artery aneurysms, which had progressed to giant aneurysms, normalized by 6month follow-up suggesting a potential beneficial role of IL-1 blockade in vascular injury/remodelling [63]. Shafferman and colleagues reported an 11week-old female with KD complicated by macrophage activation syndrome refractory to IVIG and high-dose glucocorticosteroids [64]. Anakinra was instituted due to high suspicion for macrophage activation syndrome and a dramatic clinical improvement was observed, but repeat echocardiography revealed diffuse enlargement of the entire coronary artery system and one dose of infliximab was given in addition to anakinra and corticosteroids. Corticosteroids and anakinra were tapered off during the next 5 months. Repeat echocardiography at 8-month follow-up revealed significant improvement with only 


\section{Conclusions}

mild dilatation [64]. Recent discoveries supporting the role of IL-1 in KD have led to two phase 2 clinical trials for anakinra in IVIG-resistant KD children (NCT02179853, NCT02390596).

Overall, IL-1 blockade has a good safety profile [77-79]. Similar to all biologics suppressing the immune system, the risk for pathogenic bacterial infections increases with IL-1 blockade; however, the occurrence of opportunistic infections is rare [77]. Even though there are no reports indicating an increased risk for malignancy with IL-1 blockade, the effects of long-term anti-IL-1 therapy on the natural defenses against malignancies are unknown [77]. As with TNF inhibition, the optimal dosage and treatment protocol remains to be determined and long-term safety data are lacking. The results of the ongoing clinical trials are awaited eagerly and may clarify some of these questions.

Lessons learned from pathobiology have identified TNF $\alpha$ and IL-1 $\beta$ as important mediators of inflammation in KD. Mechanistic studies in pre-clinical models of disease partnered with clinical correlates in affected children strengthen the evidence from the bench to the bedside. Clinical use of biologic agents targeting these two soluble mediators of inflammation in children with IVIG-resistant disease is widespread, but despite considerable efforts, adequately powered, randomized, controlled and prospective trials are lacking. Beneficial effects for TNF blockade on shortening fever duration, length of hospitalization and decreasing biochemical markers of inflammation have been described in small case series and clinical trials, but no significant effect is seen on coronary outcome. The use of therapeutic agents to inhibit TNF-mediated elastolysis is part of standard therapy in some countries and has ongoing trials in others. The identification of an IL-1 $\beta$ signature in KD is more recent as is the use of IL-1 inhibitors in the clinical setting. Only case reports exist in the literature, but several clinical trials are underway to assess their efficacy in treatment of recalcitrant disease and to assess the effect on coronary outcome in addition to duration of fever. International collaborations have been the cornerstone of our expanding knowledge of unique molecular signatures in children with KD. This same spirit of collaboration is needed to adequately power clinical trials that will define the therapeutic applications, so that as our understanding of pathobiology increases, so too will the precision of our treatment decisions.

\section{Acknowledgments}

FAA is supported by the Rhyner-Bangerter Fondation, Starr-Foundation, Swiss League against Rheumatism, Foundation W!, Alberta Children's Hospital Research Institute Foundation, Dawson Jarock Foundation and SickKids Foundation. RSMY is supported by the Hak-Ming and Deborah Chiu Chair in Pediatric Translational Research. 


\section{Compliance with Ethical Standards}

\section{Conflict of Interest}

Florence A. Aeschlimann declares that she has no conflict of interest.

Rae S. M. Yeung declares that she has no conflict of interest.

\section{Human and Animal Rights and Informed Consent}

With regard to the authors' research cited in this paper, all procedures performed in studies involving human participants were in accordance with the ethical standards of the institutional and/or national research committee and with the 1964 Helsinki Declaration and its later amendments or comparable ethical standards. In addition, all applicable international, national, and/or institutional guidelines for the care and use of animals were followed.

\section{References and Recommended Reading}

Papers of particular interest, published recently, have been highlighted as:

- Of importance

$\bullet \quad$ Of major importance

1. $\quad$ Newburger JW, Takahashi M, Gerber MA, Gewitz MH, Tani LY, Burns JC, et al. Diagnosis, treatment, and longterm management of Kawasaki disease: a statement for health professionals from the Committee on Rheumatic Fever, Endocarditis, and Kawasaki Disease, Council on Cardiovascular Disease in the Young, American Heart Association. Pediatrics. 2004;4(6):1708-33.

Most recent American Heart Association Guidelines

2. Luca NJ, Yeung RS. Epidemiology and management of Kawasaki disease. Drugs. 2012;72(8):1029-38.

3. Uehara R, Belay ED. Epidemiology of Kawasaki disease in Asia, Europe, and the United States. J Epidemiol. 2012;22(2):79-85.

4. Burgner D, Harnden A. Kawasaki disease: what is the epidemiology telling us about the etiology? Int I Infect Dis. 2005;9(4):185-94.

5. Leung DY, Meissner HC, Fulton DR, Murray DL, Kotzin BL, Schlievert PM. Toxic shock syndrome toxinsecreting Staphylococcus aureus in Kawasaki syndrome. Lancet. 1993;342(8884):1385-8.

6. Yeung RSM. The etiology of Kawasaki disease: a superantigen-mediated process. Prog Pediatr Cardiol. 2004;19:115-22.

7. Principi N, Rigante D, Esposito S. The role of infection in Kawasaki syndrome. J Infect. 2013;67(1):1-10.

8. Greco A, De Virgilio A, Rizzo MI, Tombolini M, Gallo A, Fusconi M, et al. Kawasaki disease: an evolving paradigm. Autoimmun Rev. 2015;14(8):703-9.

9. Leung DY, Geha RS, Newburger JW, Burns JC, Fiers W, Lapierre LA, et al. Two monokines, interleukin 1 and tumor necrosis factor, render cultured vascular endothelial cells susceptible to lysis by antibodies circulating during Kawasaki syndrome. J Exp Med. 1986;164(6):1958-72.
10. Tremoulet AH, Jain S, Jaggi P, Jimenez-Fernandez $\mathrm{S}$, Pancheri JM, Sun X, et al. Infliximab for intensification of primary therapy for Kawasaki disease: a phase 3 randomised, double-blind, placebo-controlled trial. Lancet. 2014;383(9930):1731-8.

Recent RCT of TNF inhibition in KD.

11. Ashouri N, Takahashi M, Dorey F, Mason W. Risk factors for nonresponse to therapy in Kawasaki disease. J Pediatr. 2008;153(3):365-8.

12. Burns JC, Capparelli EV, Brown JA, Newburger JW, Glode MP. Intravenous gamma-globulin treatment and retreatment in Kawasaki disease. US/Canadian Kawasaki Syndrome Study Group. Pediatr Infect Dis J. 1998;17(12):1144-8.

13. Wei M, Huang M, Chen S, Huang G, Huang M, Qiu D, et al. A multicenter study of intravenous immunoglobulin non-response in Kawasaki disease. Pediatr Cardiol. 2015;36(6):1166-72.

14. Harada K. Intravenous gamma-globulin treatment in Kawasaki disease. Acta Paediatr Jpn. 1991;33(6):805-10.

15. Iwasa M, Sugiyama K, Ando T, Nomura H, Katoh T, Wada Y. Selection of high-risk children for immunoglobulin therapy in Kawasaki disease. Prog Clin Biol Res. 1987;250:543-4.

16. Kobayashi $\mathrm{T}$, Inoue $\mathrm{Y}$, Takeuchi $\mathrm{K}$, Okada $\mathrm{Y}$, Tamura $\mathrm{K}$, Tomomasa T, et al. Prediction of intravenous immunoglobulin unresponsiveness in patients with Kawasaki disease. Circulation. 2006;113(22):2606-12.

17. Davies S, Gold-von SG. Should infliximab be used as an adjuvant to IVIG in the treatment of children with Kawasaki disease who are at high risk for resistance to conventional therapy? Pediatr Cardiol. 2013;34(7):1756. 
18. Mearns BM. Vasculitis syndromes: phase III trial of infliximab in Kawasaki disease. Nat Rev Rheumatol. 2014;10(4):198.

19.• Kobayashi T, Saji T, Otani T, Takeuchi K, Nakamura T, Arakawa $\mathrm{H}$, et al. Efficacy of immunoglobulin plus prednisolone for prevention of coronary artery abnormalities in severe Kawasaki disease (RAISE study): a randomised, open-label, blinded-endpoints trial. Lancet. 2012;379(9826):1613-20.

One of the largest trials of any therapeutic agent in KD with good data on steroid use in KD.

20. Maury CP, Salo E, Pelkonen P. Circulating interleukin1 beta in patients with Kawasaki disease. N Engl J Med. 1988;319(25):1670-1.

21. de Jager W, Bourcier K, Rijkers GT, Prakken BJ, SeyfertMargolis V. Prerequisites for cytokine measurements in clinical trials with multiplex immunoassays. BMC Immunol. 2009;10:52.

22. Friebe A, Volk HD. Stability of tumor necrosis factor alpha, interleukin 6 , and interleukin 8 in blood samples of patients with systemic immune activation. Arch Pathol Lab Med. 2008;132(11):1802-6.

23. Matheson LA, Duong TT, Rosenberg AM, Yeung RS. Assessment of sample collection and storage methods for multicenter immunologic research in children. J Immunol Methods. 2008;339(1):82-9.

24. Furukawa S, Matsubara T, Umezawa Y, Okumura K, Yabuta K. Serum levels of p60 soluble tumor necrosis factor receptor during acute Kawasaki disease. J Pediatr 1994; 124(5 Pt 1):721-5.

25. Lang BA, Silverman ED, Laxer RM, Rose V, Nelson DL, Rubin LA. Serum-soluble interleukin-2 receptor levels in Kawasaki disease. J Pediatr. 1990;116(4):592-6.

26. Matsubara T, Furukawa S, Yabuta K. Serum levels of tumor necrosis factor, interleukin 2 receptor, and interferon-gamma in Kawasaki disease involved coronary-artery lesions. Clin Immunol Immunopathol. 1990;56(1):29-36.

27. Wang Y, Wang W, Gong F, Fu S, Zhang Q, Hu J, et al. Evaluation of intravenous immunoglobulin resistance and coronary artery lesions in relation to Th1/Th2 cytokine profiles in patients with Kawasaki disease. Arthritis Rheum. 2013;65(3):805-14.

28. Hui-Yuen JS, Duong TT, Yeung RS. TNF-alpha is necessary for induction of coronary artery inflammation and aneurysm formation in an animal model of Kawasaki disease. J Immunol. 2006;176(10):6294-301.

29. Lau AC, Duong TT, Ito S, Yeung RS. Matrix metalloproteinase 9 activity leads to elastin breakdown in an animal model of Kawasaki disease. Arthritis Rheum. 2008;58(3):854-63.

30. Lau AC, Duong TT, Ito S, Wilson GJ, Yeung RS. Inhibition of matrix metalloproteinase-9 activity improves coronary outcome in an animal model of Kawasaki disease. Clin Exp Immunol. 2009;157(2):300-9.

31. Lau AC, Duong TT, Ito S, Yeung RS. Intravenous immunoglobulin and salicylate differentially modulate pathogenic processes leading to vascular damage in a model of Kawasaki disease. Arthritis Rheum. 2009;60(7):2131-41.

32. Andreakos ET, Foxwell BM, Brennan FM, Maini RN, Feldmann M. Cytokines and anti-cytokine biologicals in autoimmunity: present and future. Cytokine Growth Factor Rev. 2002;13(4-5):299-313.

33. Biedermann BC. Vascular endothelium: checkpoint for inflammation and immunity. News Physiol Sci.

2001;16:84-8

34. Rios-Navarro C, de Pablo C, Collado-Diaz V, Orden S, Blas-Garcia A, Martinez-Cuesta MA, et al. Differential effects of anti-TNF-alpha and anti-IL-12/23 agents on human leukocyte-endothelial cell interactions. Eur J Pharmacol. 2015;765:355-65.

35. Choi J, Enis DR, Koh KP, Shiao SL, Pober JS. T lymphocyte-endothelial cell interactions. Annu Rev Immunol. 2004;22:683-709.

36. Furukawa S, Imai K, Matsubara T, Yone K, Yachi A, Okumura $\mathrm{K}$, et al. Increased levels of circulating intercellular adhesion molecule 1 in Kawasaki disease. Arthritis Rheum. 1992;35(6):672-7.

37. Wong $M$, Silverman ED, Fish EN. Evidence for RANTES, monocyte chemotactic protein-1, and macrophage inflammatory protein-1 beta expression in Kawasaki disease. J Rheumatol. 1997;24(6):1179-85.

38. Sakata K, Hamaoka K, Ozawa S, Niboshi A, Yahata T, Fujii $\mathrm{M}$, et al. Matrix metalloproteinase-9 in vascular lesions and endothelial regulation in Kawasaki disease. Circ J. 2010;74(8):1670-5.

39. Gavin PJ, Crawford SE, Shulman ST, Garcia FL, Rowley AH. Systemic arterial expression of matrix metalloproteinases 2 and 9 in acute Kawasaki disease. Arterioscler Thromb Vasc Biol. 2003;23(4):576-81.

40. Stringer E, Yeung RSM. Pathogenesis of Kawasaki disease: the central role of TNF-a. Futur Rheumatol. 2008;3:69-77.

41. Chan WC, Duong TT, Yeung RS. Presence of IFN-gamma does not indicate its necessity for induction of coronary arteritis in an animal model of Kawasaki disease. J Immunol. 2004;173(5):3492-503.

42. Dinarello CA. A clinical perspective of IL-1beta as the gatekeeper of inflammation. Eur J Immunol. 2011;41(5):1203-17.

43. Martinon F, Aksentijevich I. New players driving inflammation in monogenic autoinflammatory diseases. Nat Rev Rheumatol. 2015;11(1):11-20.

44. Russo RA, Brogan PA. Monogenic autoinflammatory diseases. Rheumatology (Oxford). 2014;53(11):192739.

45. Dinarello CA. The many worlds of reducing interleukin-1. Arthritis Rheum. 2005;52(7):1960-7.

46. Thornberry NA, Bull HG, Calaycay JR, Chapman KT, Howard AD, Kostura MJ, et al. A novel heterodimeric cysteine protease is required for interleukin-1 beta processing in monocytes. Nature. 1992;356(6372):768-74.

47. Popper SJ, Shimizu C, Shike H, Kanegaye JT, Newburger JW, Sundel RP, et al. Gene-expression 
patterns reveal underlying biological processes in Kawasaki disease. Genome Biol. 2007;8(12):R261.

48. Fury W, Tremoulet AH, Watson VE, Best BM, Shimizu C, Hamilton J, et al. Transcript abundance patterns in Kawasaki disease patients with intravenous immunoglobulin resistance. Hum Immunol. 2010;71(9):86573.

49. Weng KP, Hsieh KS, Ho TY, Huang SH, Lai CR, Chiu YT, et al. IL-1B polymorphism in association with initial intravenous immunoglobulin treatment failure in Taiwanese children with Kawasaki disease. Circ J. 2010;74(3):544-51.

50. Leung DY, Cotran RS, Kurt-Jones E, Burns JC, Newburger JW, Pober JS. Endothelial cell activation and high interleukin-1 secretion in the pathogenesis of acute Kawasaki disease. Lancet. 1989;2(8675):1298302.

51. Suzuki H, Uemura S, Tone S, lizuka T, Koike M, Hirayama K, et al. Effects of immunoglobulin and gamma-interferon on the production of tumour necrosis factor-alpha and interleukin- 1 beta by peripheral blood monocytes in the acute phase of Kawasaki disease. Eur J Pediatr. 1996;155(4):291-6.

52. Okitsu-Negishi S, Furusawa S, Kawa Y, Hashira S, Ito S, Hiruma F, et al. Suppressive effect of intravenous immunoglobulins on the activity of interleukin-1. Immunol Res. 1994;13(1):49-55.

53. Onouchi Y, Ozaki K, Burns JC, Shimizu C, Terai M, Hamada $\mathrm{H}$, et al. A genome-wide association study identifies three new risk loci for Kawasaki disease. Nat Genet. 2012;44(5):517-21.

54. Alphonse MP, Duong TT, Shimizu C, Hoang LT, McCrindle BW, Franco A, et al. Abstract O.21: Inositol 1,4,5, triphosphate 3-kinase c regulates nlrp3 inflammasome activation in kawasaki disease. Circulation. 2015;131(Suppl 2):AO21-AO21.

55. Horng T. Calcium signaling and mitochondrial destabilization in the triggering of the NLRP3 inflammasome. Trends Immunol. 2014;35(6):25361.

56. Lou J, Xu S, Zou L, Zhong R, Zhang T, Sun Y, et al. A functional polymorphism, rs28493229, in ITPKC and risk of Kawasaki disease: an integrated meta-analysis. Mol Biol Rep. 2012;39(12):11137-44.

57. Hoang LT, Shimizu C, Ling L, Naim AN, Khor CC, Tremoulet AH, et al. Global gene expression profiling identifies new therapeutic targets in acute Kawasaki disease. Genome Med. 2014;6(11):541.

IL-1 $\beta$ gene expresssion signature in children with $\mathrm{KD}$.

58. Lee Y, Schulte DJ, Shimada K, Chen S, Crother TR, Chiba N, et al. Interleukin-1beta is crucial for the induction of coronary artery inflammation in a mouse model of Kawasaki disease. Circulation.

2012;125(12):1542-50.

59. Lee Y, Wakita D, Dagvadorj J, Shimada K, Chen S, Huang G, et al. IL-1 signaling is critically required in stromal cells in Kawasaki disease vasculitis mouse model: role of both IL-1alpha and IL-1beta. Arterioscler Thromb Vasc Biol. 2015;35(12):2605-16.
60. Dinarello CA. Biologic basis for interleukin-1 in disease. Blood. 1996;87(6):2095-147.

61. Hoffman HM, Rosengren S, Boyle DL, Cho JY, Nayar J, Mueller JL, et al. Prevention of cold-associated acute inflammation in familial cold autoinflammatory syndrome by interleukin-1 receptor antagonist. Lancet. 2004;364(9447):1779-85.

62. Bujak M, Frangogiannis NG. The role of IL-1 in the pathogenesis of heart disease. Arch Immunol Ther Exp (Warsz). 2009;57(3):165-76.

63. Cohen S, Tacke CE, Straver B, Meijer N, Kuipers IM, Kuijpers TW. A child with severe relapsing Kawasaki disease rescued by IL-1 receptor blockade and extracorporeal membrane oxygenation. Ann Rheum Dis. 2012;71(12):2059-61.

64. Shafferman A, Birmingham JD, Cron RQ. High dose Anakinra for treatment of severe neonatal Kawasaki disease: a case report. Pediatr Rheumatol Online J. 2014;12:26.

65. Son MB, Gauvreau K, Burns JC, Corinaldesi E, Tremoulet AH, Watson VE, et al. Infliximab for intravenous immunoglobulin resistance in Kawasaki disease: a retrospective study. J Pediatr. 2011;158(4):6449. e1.

66. Burns JC, Best BM, Mejias A, Mahony L, Fixler DE, Jafri HS, et al. Infliximab treatment of intravenous immunoglobulin-resistant Kawasaki disease. J Pediatr. 2008;153(6):833-8.

67. Burns JC, Mason WH, Hauger SB, Janai H, Bastian JF, Wohrley JD, et al. Infliximab treatment for refractory Kawasaki syndrome. J Pediatr. 2005;146(5):662-7.

68. Mori M, Imagawa T, Hara R, Kikuchi M, Hara T, Nozawa $T$, et al. Efficacy and limitation of infliximab treatment for children with Kawasaki disease intractable to intravenous immunoglobulin therapy: report of an open-label case series. J Rheumatol.

2012;39(4):864-7.

69. Hirono K, Kemmotsu Y, Wittkowski H, Foell D, Saito $\mathrm{K}$, Ibuki $\mathrm{K}$, et al. Infliximab reduces the cytokine-mediated inflammation but does not suppress cellular infiltration of the vessel wall in refractory Kawasaki disease. Pediatr Res. 2009;65(6):696-701.

70. Masuda H, Abe J, Oana S, Ishiguro A, Tsuchida N, Sakai $\mathrm{H}$, et al. Abstract O.51: Effects of anti-TNF-alpha antibody therapy on IVIG-resistant patients with Kawasaki disease. Circulation. 2015;131(Suppl 2):AO51-AO51.

71. Choueiter NF, Olson AK, Shen DD, Portman MA. Prospective open-label trial of etanercept as adjunctive therapy for kawasaki disease. J Pediatr.

2010;157(6):960-6. e1.

72. Benseler SM, McCrindle BW, Silverman ED, Tyrrell PN, Wong J, Yeung RS. Infections and Kawasaki disease: implications for coronary artery outcome. Pediatrics. 2005;116(6):e760-6.

73. Kanai T, Ishiwata T, Kobayashi T, Sato H, Takizawa M, Kawamura Y, et al. Ulinastatin, a urinary trypsin inhibitor, for the initial treatment of patients with Kawasaki disease: a retrospective study. Circulation. 2011;124(25):2822-8. 
74. $\quad$ Research Committee of the Japanese Society of Pediatric C, Cardiac Surgery Committee for Development of Guidelines for Medical Treatment of Acute Kawasaki D. Guidelines for medical treatment of acute Kawasaki disease: report of the Research Committee of the Japanese Society of Pediatric Cardiology and Cardiac Surgery (2012 revised version). Pediatr Int. 2014;56(2):135-58.

Japanese guidelines for treatment of KD.

75. Tremoulet AH. The role of statins in inflammatory vasculitides. Autoimmunity. 2015;48(3):177-80.

76. Blankier S, McCrindle BW, Ito S, Yeung RS. The role of atorvastatin in regulating the immune response leading to vascular damage in a model of Kawasaki disease. Clin Exp Immunol. 2011;164(2):193-201.

77. Dinarello CA, Simon A, van der Meer JW. Treating inflammation by blocking interleukin- 1 in a broad spectrum of diseases. Nat Rev Drug Discov. 2012;11(8):633-52.

78. Federici S, Martini A, Gattorno M. The central role of anti-IL-1 blockade in the treatment of monogenic and multi-factorial autoinflammatory diseases. Front Immunol. 2013;4:351.

79. Jesus AA, Goldbach-Mansky R. IL-1 blockade in autoinflammatory syndromes. Annu Rev Med. 2014;65:223-44. 